D) Check for updates

Cite this: New J. Chem., 2018

42, 14009

DOI: $10.1039 / c 8 n j 90073 f$

rsc.li/njc

\section{Correction: $\mathrm{CuCl}$ heterogenized on} metformine-modified multi walled carbon nanotubes as a recyclable nanocatalyst for Ullmann-type $\mathrm{C}-\mathrm{O}$ and $\mathrm{C}-\mathrm{N}$ coupling reactions

\author{
Elham Akhavan Taheri, ${ }^{a}$ Saba Hemmati, ${ }^{b}$ Malak Hekmati ${ }^{a}$ and Hojat Veisi*b
}

Correction for ' $\mathrm{CuCl}$ heterogenized on metformine-modified multi walled carbon nanotubes as a recyclable nanocatalyst for Ullmann-type $\mathrm{C}-\mathrm{O}$ and $\mathrm{C}-\mathrm{N}$ coupling reactions' by Elham Akhavan Taheri et al., New J. Chem., 2018, 42, 2782-2789.

The first author's name is incorrect in the published article. The correct author name is Elham Akhavan Taheri, as shown above. The Royal Society of Chemistry apologises for these errors and any consequent inconvenience to authors and readers.

\footnotetext{
${ }^{a}$ Department of Pharmaceutical Chemistry, Faculty of Pharmaceutical Chemistry, Pharmaceutical Sciences Branch, Islamic Azad University, (IAUPS), Tehran, Iran

${ }^{b}$ Department of Chemistry, Payame Noor University, Tehran, Iran. E-mail: hojatveisi@yahoo.com
} 